\title{
Extragastrointestinal Stromal Tumor Presenting as a Recurrent Vaginal Mass: Case Report
}

This article was published in the following Dove Press journal: OncoTargets and Therapy

\author{
Shuai Liu (1D) \\ Pan $\operatorname{Pan}^{2}$ \\ Bing $\mathrm{Han}^{3}$ \\ Jingnan Wang' \\ Meili Sun' \\ Yuping Sun' \\ 'Department of Oncology, Jinan Central \\ Hospital Affiliated to Shandong \\ University; Jinan Central Hospital \\ Affiliated to Shandong First Medical \\ University, Jinan, 2500I3, Shandong, \\ People's Republic of China; ${ }^{2}$ Department \\ of Pathology, Jinan Central Hospital \\ Affiliated to Shandong University; Jinan \\ Central Hospital Affiliated to Shandong \\ First Medical University, Jinan, 2500I3, \\ Shandong, People's Republic of China; \\ ${ }^{3}$ Department of Obstetrics and \\ Gynecology, Qilu Hospital, Shandong \\ University, Jinan, 2500 I2, Shandong, \\ People's Republic of China
}

\begin{abstract}
Gastrointestinal stromal tumors (GISTs) are the dominant mesenchymal tumors of the digestive tract. Extragastrointestinal stromal tumors (EGISTs) usually originate outside the gastrointestinal tract without connection to the gastric or intestinal wall. However, EGISTs arising from the vaginal wall are very rare. Here, we report a case of EGIST that occurred in the vagina of a 60 -year-old woman. The tumor was present in the posterior vaginal wall. It was surgically excised, and histological examination revealed spindle cell morphology with up to 14 mitoses per 50 high power field (HPF) and necrosis with the tumor-negative margins. Immunohistochemical analyses showed strongly positive CD34, CD117, and DOG-1 expression, but negative SMA, S-100, CD10, desmin, and actin expression. The patient underwent surgery and is currently being followed up. A literature review of EGSTs and treatments is also discussed in this report.
\end{abstract}

Keywords: extragastrointestinal stromal tumors, vagina, c-kit, mutation

\section{Introduction}

Gastrointestinal stromal tumors (GISTs) are the primary type of mesenchymal tumors of the gastrointestinal tract. ${ }^{1}$ Typically, most GISTs occur in the stomach, but they are also known to occur in the small intestine, rectum, colon, and esophagus. ${ }^{2}$ Some GISTs arises from the alimentary canal such as the omentum, mesentery, or retroperitoneum. GISTs originating from atypical sites are defined as extragastrointestinal stromal tumors (EGISTs). ${ }^{3-5}$ Typically, 95\% GISTs are positive for KIT (CD117) and CD34 expression, which are the most significant markers for EGIST diagnosis. In addition, smooth muscle actins (SMA) and heavy caldesmon are always expressed, but desmin is often absent. Here, we report an unusual case of EGIST that presented in the vagina. We further explored the clinical behavior and prognostic factors of EGIST by conducting a literature review.

\section{Case}

A 60 -year-old, gravida 2, para 2 Chinese woman presented with a posterior vaginal mass. The lesion had been present for 2 years, before being first diagnosed in December 2014; the patient complained of vaginal bleeding. She did not experience astriction or abdominal pain. Physical examination revealed a mass measuring 4-6 $\mathrm{cm}$ in the posterior vaginal wall. Ultrasound examination and CT scanning showed a non-homogenous hypoechoic mass with diffuse hypervascularity on the posterior vaginal wall (Figure 1). The overlying vaginal mucosa was intact. A rectal examination was performed and was unremarkable. The lesion was completely 


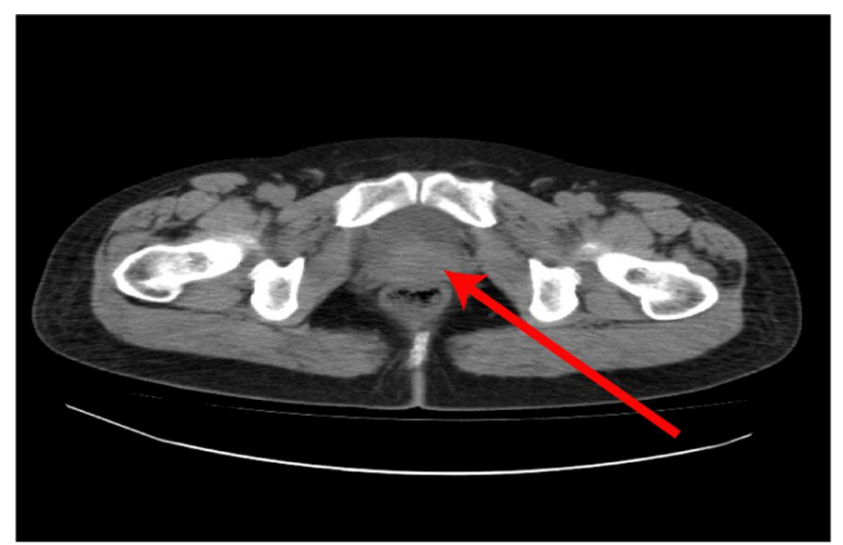

Figure I A CT scan of the pelvis showing a mass arising from the posterior wall of the vagina. The tumor mass showed invasion of the posterior vaginal wall without rectal invasion or pelvic floor musculature (red arrow).

resected with negative margins and sent for pathologic evaluation. Gross examination showed a whitish, solid mass measuring $5.5 \times 3.3 \times 3 \mathrm{~cm}$. Microscopically, the tumor comprised densely spindled cells with an interlacing fascicular pattern. The spindle cells showed high nuclear abnormalities with elongated plump nuclei and coarse chromatin texture and fibrillary cytoplasm. Coagulative tumor necrosis was identified. Up to 14 mitotic counts per 50 high power field (HPF) were counted. Immunohistochemical staining was strongly positive for DOG-1, c-Kit protein (CD117), and CD34 and negative for SMA, S-100, CD10, desmin, and actin (Figure 2). The $\mathrm{Ki}-67^{+}$cell populations were up to $10 \%$ in the tumor area. The tumor was clinically diagnosed as an EGIST based on the criteria for malignancy. The patient did not undergo further adjuvant therapy and has been well for the last 5 years without any recurrence.

\section{Discussion}

According to reports thus far, GISTs usually occur in adults aged $>40$ years (mean age: $55-60$ years) and are rare in children. ${ }^{6,7}$ The most common GIST sites are stomach $(60 \%)$, small intestine $(25 \%)$, colon/rectum $(10 \%)$. Stromal tumors arising outside the digestive tract (EGISTs) are uncommon and comprise only about $5 \%$ of all GISTs. To our best knowledge, only 15 cases of GIST have been reported to originate from the vagina and rectovaginal septum, since 2004 (Table 1). ${ }^{8-18}$ The median age of patients was 48 years, ranging from 15 to 75 years. Tumor diameters ranged from 2 to $8 \mathrm{~cm}$. Ten tumors were located in the rectovaginal septum. Five tumors were located in the vagina. EGIST in the pelvic cavity often results in symptoms such as instant bleeding, constipation, and pollakiuria because of tumor infiltration and compression. In the current case, the patient presented with a palpable vaginal mass with bleeding, but she did not have any abdominal pain, rectal bleeding, or bowel
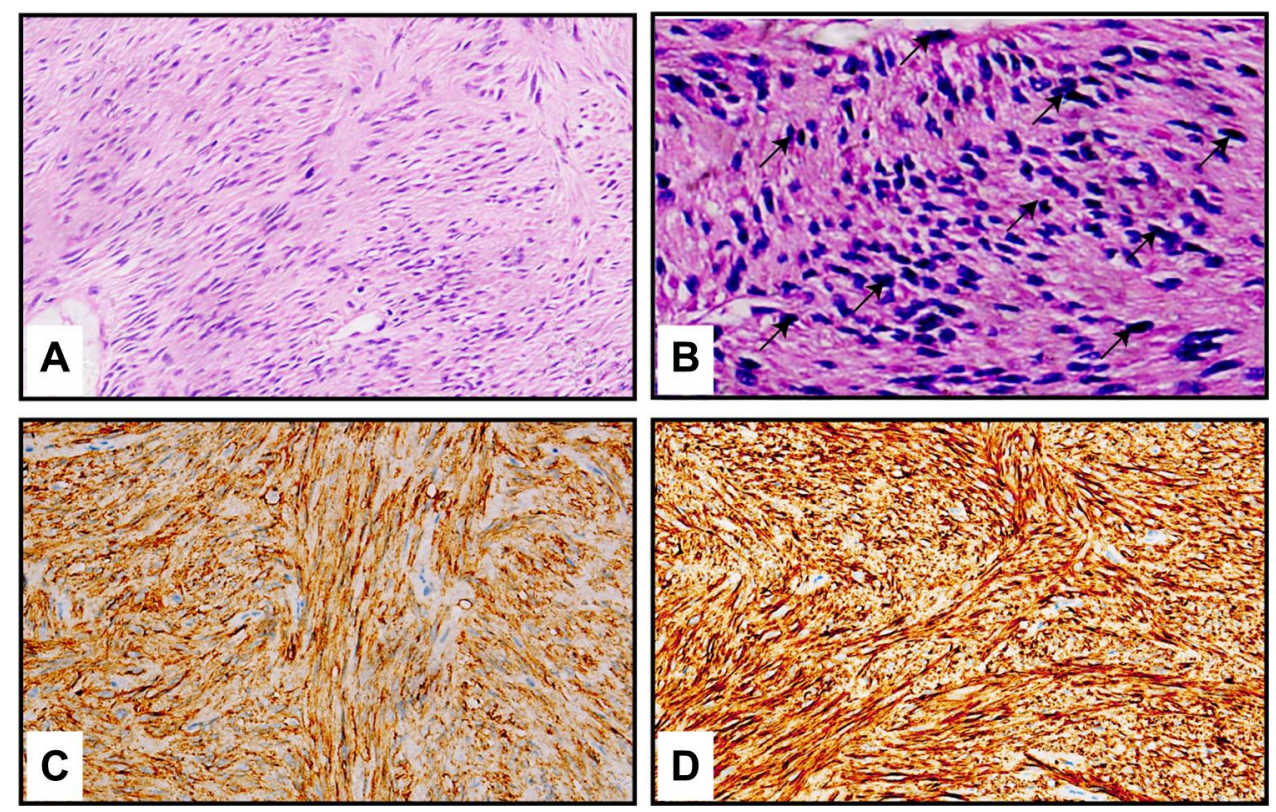

Figure 2 Pathological results of the tumor. (A) Hematoxylin and eosin (H \& E) staining showed fascicles of cellular spindle cells within the tumor (200x magnification). (B) The biopsy specimen showed spindle cell proliferation with active mitosis (black arrows) with H \& E staining (400× magnification). (C) Immunohistochemical staining showed diffuse and strong DOG-I expression in the tumor cells (400x magnification). (D) Immunohistochemical staining showed diffuse and strong CDII 7 expression in the tumor cells (400× magnification). 


\begin{tabular}{|c|c|c|c|c|c|c|c|c|c|}
\hline 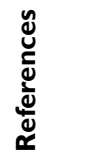 & $\sigma$ & $\simeq$ & $\underline{m}$ & \pm & $=$ & & & $\underline{\underline{n}}$ & \\
\hline 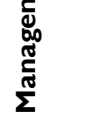 & 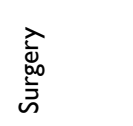 & $\begin{array}{l}\frac{\lambda}{\overline{0}} \\
\stackrel{0}{=} \\
\bar{\omega}\end{array}$ & 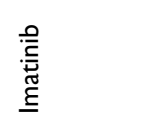 & 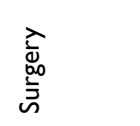 & 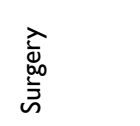 & 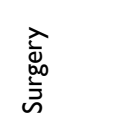 & 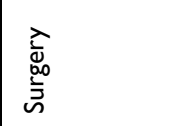 & 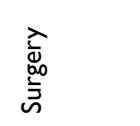 & 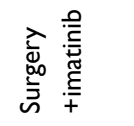 \\
\hline 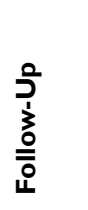 & 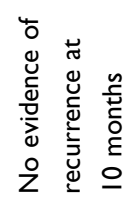 & 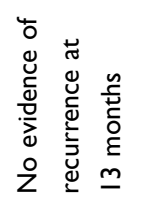 & $\begin{array}{l}\frac{5}{3} \\
\frac{0}{5} \\
\frac{5}{5}\end{array}$ & 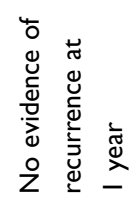 & 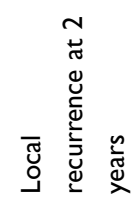 & 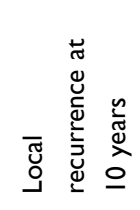 & $\begin{array}{l}\frac{5}{3} \\
0 \\
\frac{5}{5} \\
5\end{array}$ & 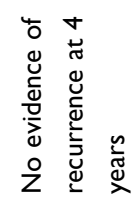 & 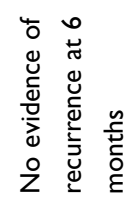 \\
\hline$\stackrel{U}{\underline{I}}$ & 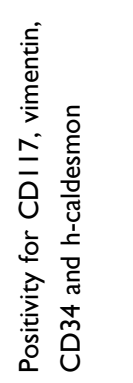 & 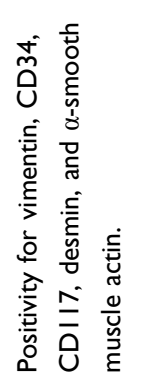 & 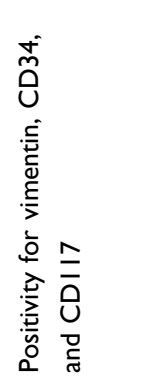 & 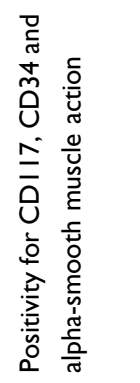 & 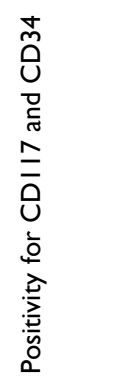 & 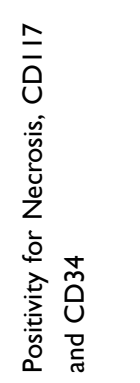 & 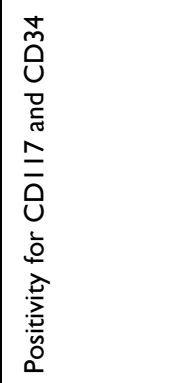 & 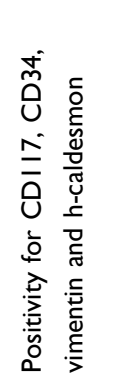 & 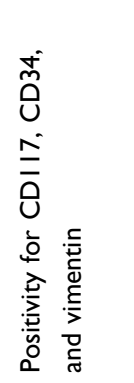 \\
\hline 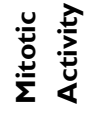 & 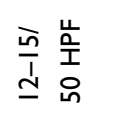 & $\stackrel{O}{\stackrel{0}{I}}$ & 员 嵩 & 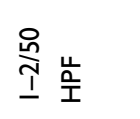 & 옹 ㄴㅡㅗ & 号荇 & 总 & $\stackrel{\text { 온 }}{\frac{u}{T}}$ & 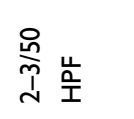 \\
\hline 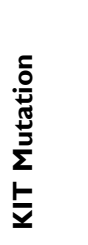 & $\begin{array}{l}\frac{5}{3} \\
0 \\
\frac{5}{5} \\
5\end{array}$ & $\begin{array}{l}\frac{5}{3} \\
0 \\
\frac{5}{5} \\
5\end{array}$ & $\begin{array}{l}\frac{5}{3} \\
0 \\
\frac{5}{5} \\
5\end{array}$ & $\begin{array}{l}\frac{5}{3} \\
0 \\
\frac{5}{5} \\
5\end{array}$ & 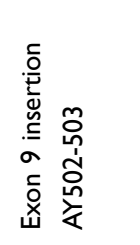 & 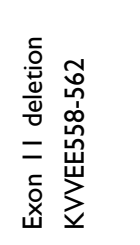 & 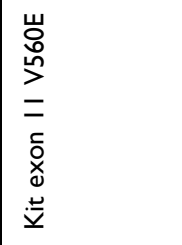 & $\begin{array}{l}\frac{5}{5} \\
0 \\
\frac{5}{5} \\
5\end{array}$ & 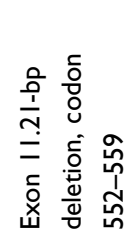 \\
\hline 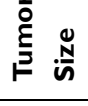 & $\stackrel{\stackrel{\sim}{+}}{+}$ & $\infty$ & $\infty$ & $\wedge$ & $\nabla$ & 0 & $\infty$ & $\stackrel{\stackrel{n}{m}}{m}$ & in \\
\hline بَّ & 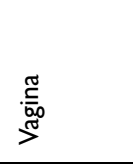 & 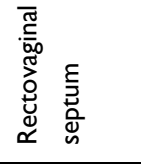 & 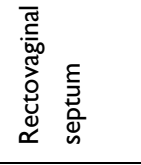 & 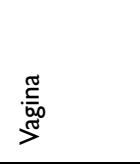 & 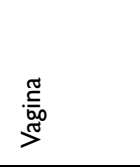 & 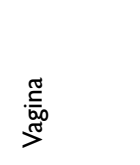 & 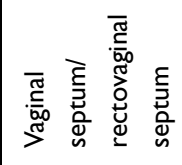 & 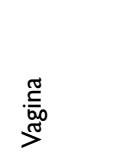 & 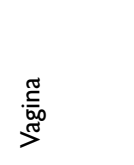 \\
\hline 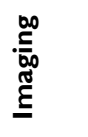 & 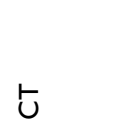 & 七 & 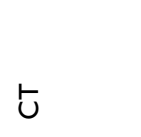 & 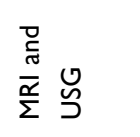 & $\begin{array}{l}\frac{5}{3} \\
0 \\
\frac{5}{5} \\
5\end{array}$ & $\begin{array}{l}\frac{5}{0} \\
0 \\
\frac{v}{5} \\
5\end{array}$ & $\begin{array}{l}\frac{5}{3} \\
0 \\
\frac{5}{5} \\
5\end{array}$ & $\begin{array}{l}\frac{5}{5} \\
0 \\
\frac{5}{5} \\
5\end{array}$ & $\begin{array}{l}\frac{5}{3} \\
0 \\
\frac{5}{5} \\
5\end{array}$ \\
\hline$\underset{8}{\stackrel{0}{\&}}$ & $\stackrel{n}{\wedge}$ & $\stackrel{+}{n}$ & $\stackrel{\circ}{\circ}$ & $\stackrel{\infty}{m}$ & $\stackrel{\circ}{m}$ & $\stackrel{\infty}{+}$ & $\overline{0}$ & $\mathcal{F}$ & $\stackrel{\circ}{\circ}$ \\
\hline$\dot{\dot{z}} \frac{n}{0}$ & - & - & - & - & \multicolumn{3}{|l|}{$m$} & \multicolumn{2}{|l|}{$N$} \\
\hline נ̆ & 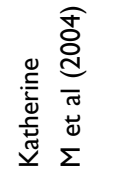 & 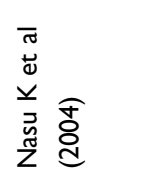 & 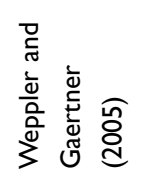 & 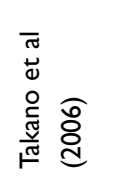 & \multicolumn{3}{|l|}{ 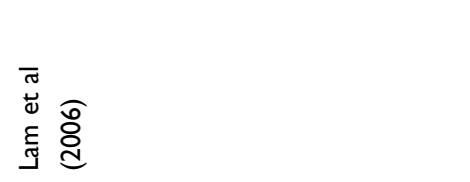 } & \multicolumn{2}{|l|}{ 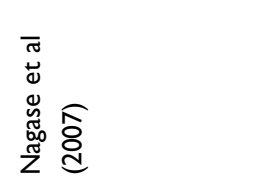 } \\
\hline
\end{tabular}




\begin{tabular}{|c|c|c|c|c|c|c|}
\hline 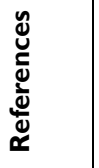 & $\underline{0}$ & $\simeq$ & 으 & $\underline{\infty}$ & $\infty$ & \\
\hline 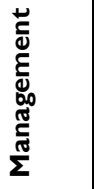 & 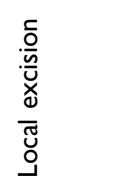 & 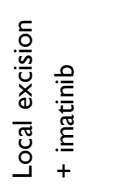 & 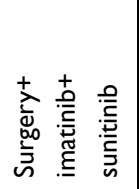 & 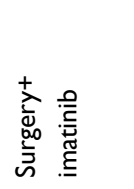 & 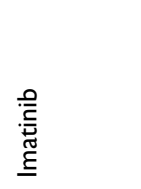 & 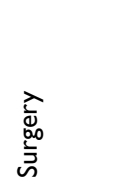 \\
\hline $\begin{array}{l}\sum_{0}^{0} \\
\vdots 3 \\
0 \\
\frac{1}{0} \\
4\end{array}$ & 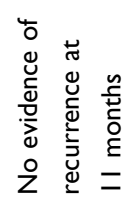 & 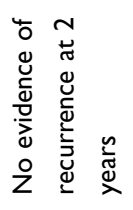 & 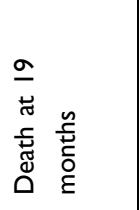 & 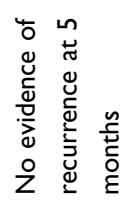 & 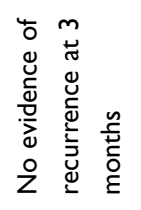 & 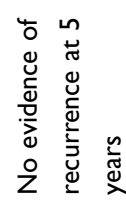 \\
\hline$\stackrel{\underline{\underline{I}}}{\underline{\underline{u}}}$ & 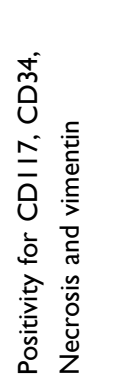 & 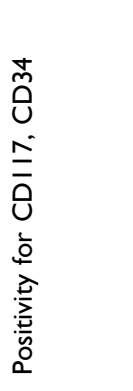 & 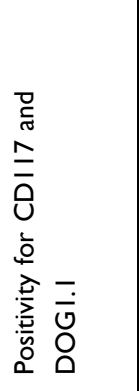 & 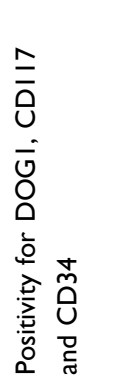 & 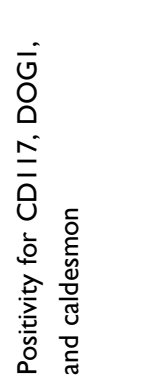 & 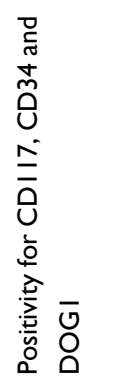 \\
\hline 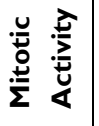 & 옹 uㅡㅁ & 员 & \begin{tabular}{l} 
号 \\
ơ \\
\multirow{1}{*}{}
\end{tabular} & 号 & 号蒋 & 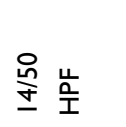 \\
\hline 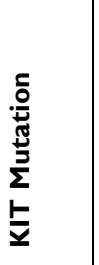 & $\begin{array}{l}\frac{5}{3} \\
\frac{0}{5} \\
\frac{5}{5}\end{array}$ & 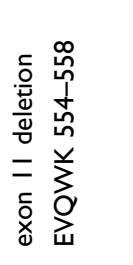 & $\begin{array}{l}\frac{5}{3} \\
\frac{0}{5} \\
\frac{5}{5}\end{array}$ & 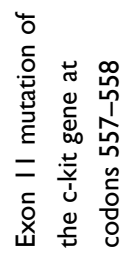 & $\begin{array}{l}\frac{5}{3} \\
0 \\
\frac{5}{5} \\
5\end{array}$ & $\begin{array}{l}\frac{5}{3} \\
\frac{0}{5} \\
\frac{5}{5}\end{array}$ \\
\hline 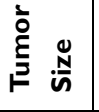 & $\infty$ & 0 & $N$ & $\stackrel{\llcorner ?}{\sim}$ & $\stackrel{\circ}{\infty}$ & $\stackrel{\text { Ln }}{n}$ \\
\hline בَّ & 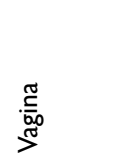 & 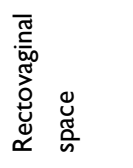 & 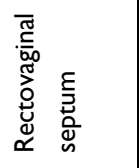 & 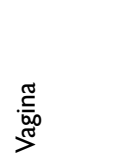 & 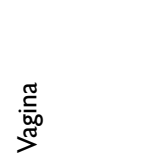 & 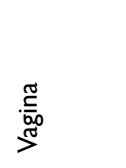 \\
\hline 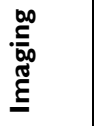 & $\begin{array}{l}\text { 巳 } \\
\text { है U U }\end{array}$ & 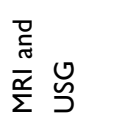 & 总 & 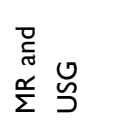 & 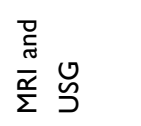 & $\begin{array}{l}\text { 巳 } \\
\text { है U U }\end{array}$ \\
\hline 品 & $\mathcal{F}$ & নి & $\underline{\underline{n}}$ & $\bar{\sigma}$ & $\stackrel{\infty}{\circledR}$ & ᄋ \\
\hline$\dot{2} \stackrel{0}{0}$ & - & - & - & - & - & - \\
\hline Uूँ & 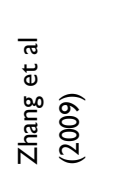 & 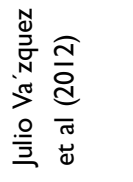 & 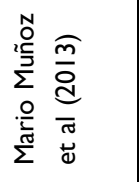 & 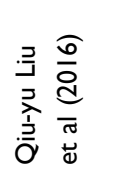 & 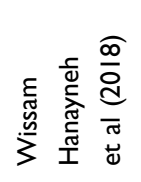 & 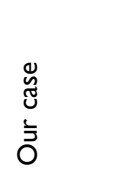 \\
\hline
\end{tabular}


dysfunction. Physical examination showed that the mass was localized to the posterior vaginal wall, but the primary sites of disease could not be identified.

In addition to the location, histologic and immunohistochemical analyses are critical for an EGIST diagnosis. The histopathological features of EGISTs comprise spindle cells (70\%), epithelioid cells $(20 \%)$, or a mixed cell type $(10 \%){ }^{19}$ Traditional tumor-associated markers such as CA 72-4 and CEA are not often used for EGIST diagnosis. CD117 (transmembrane tyrosine kinase/KIT) and CD34 are the key immunohistochemical markers for EGISTs. ${ }^{20,21}$ CD117 is expressed in the cell cytoplasm and mostly enriched in the Golgi regions. CD117 expression in cells is functionally associated with the gain-of-function mutation in KIT, causing the constitutive expression of tyrosine kinase. In the current case, immunohistochemical analyses of the tumor was negative for SMA, S-100, CD10, desmin and actin, but diffusely positive for CD34 and CD117. Furthermore, the patient's tumor cells were also positive for DOG-1, another important and sensitive marker for GISTs. Around $92 \%$ of the identified KIT mutated GISTs are positive for DOG-1, while $81 \%$ of them are positive for CD117 expression. Our results collectively suggest that this patient had an EGIST.

GISTs and EGISTs arise from the interstitial Cajal cells. $^{22}$ EGISTs are more aggressive than GISTs normally arising in common locations (the distal tract). Factors which imply a poor prognosis include high mitotic activity $(>2 / 50 \mathrm{HPF})$ and cellularity and/or the presence of tumor necrosis. In the present case, high mitotic counts (up to 14 per $50 \mathrm{HPF}$ ) were observed, suggesting that the tumor is in a high-risk category.

The traditional treatment for both GIST and EGIST is still surgical resection. ${ }^{21,23}$ However, most patients always have tumor recurrence despite complete resection of primary tumors with negative margins. Importantly, the standard systemic chemotherapy agents such as gemcitabine, epirubicin, docetaxel, and doxorubicin as well as a radiation therapy have limited therapeutic effects on GISTs. ${ }^{24}$ Recent studies suggest that most GISTs activate oncogenic "driver" mutations in the receptor tyrosine kinase (RTK) KIT gene and $P D G F R A$ gene, resulting in poor prognosis and therapy resistance. Mutations in the KIT exons 9, 11, 13, and 17 are associated with GISTs. Imatinib mesylate, a tyrosine kinase inhibitor primitively designed to treat chronic myelogenous leukemia, is the first-line drug for the treatment of unresectable and advanced GISTs. ${ }^{25}$

Furthermore, clinical response to chemotherapy in GIST patients is correlated with the KIT mutation status. It is reported that patients with a KIT exon 11 mutation appear to show better response than patients with a KIT exon 9 mutation. Multiple KIT mutations in the same GIST patient are responsible for imatinib resistance. The FDA has approved sunitinib malate (a multitargeted TKI that inhibits KIT) as a second-line treatment for GIST patients who acquire imatinib resistance or are intolerant to the drug. ${ }^{25,26}$ Regorafenib is an FDA-suggested third-line therapy drug for GIST patients. ${ }^{27,28}$ The second- and third-line treatments do not hold much promise owing to significant side effects and short effective time. ${ }^{29}$ Avapritinib (BLU285, Blueprint Medicines) is a selective KIT inhibitor for the PDGFRA and KIT activation loop mutants. ${ }^{30}$ Avapritinib was approved by the US-FDA as a 4th-line treatment for GIST with a PDGFRA exon 18 mutation (including $\mathrm{D} 842 \mathrm{~V})^{31,32}$ and for the treatment of PDGFRA D842V GIST in spite of prior therapy in the EU. ${ }^{33}$

However, despite appropriate diagnosis and treatment for EGISTs, these malignant tumors eventually become resistant to therapy with tyrosine kinase inhibitors. Therefore, further studies are urgently needed to recognize the molecular mechanisms responsible for the pathogenesis of EGISTs to precisely diagnose and provide more effective therapeutic approaches, for EGIST patients.

\section{Ethics Approval and Patient Consent}

This study was approved by the Medical Ethics Committee of Jinan Central Hospital Affiliated to Shandong University and Jinan Central Hospital Affiliated to Shandong First Medical University. Written informed consent was obtained from the patient to have case details published.

\section{Acknowledgment}

This work was supported by Shandong Medical and Health Science and Technology Development Project (grant no. 2016WS0136), Jinan Medical and Health Science and Technology Development Project (grant no. 2020-4-24), the Youth Fund from Natural Science Foundation of Shandong Province (grant no. ZR2020QH252) and the Scientific and Technical Innovation Plan in Clinical medicine of Jinan (grant no. 202019005).

\section{Disclosure}

The authors declare that they have no competing interests. 


\section{References}

1. Barghash IA, Abdul-Samad M, Oteifa M, Adesina AO. Gastrointestinal stromal tumour of the omentum: a case report. Gulf J Oncolog. 2008;(3):58-63.

2. Appelman HD. Morphology of gastrointestinal stromal tumors: historical perspectives. $J$ Surg Oncol. 2011;104(8):874-881. doi:10.1002/jso.21873

3. Kim JH, Boo YJ, Jung CW, et al. Multiple malignant extragastrointestinal stromal tumors of the greater omentum and results of immunohistochemistry and mutation analysis: a case report. World $J$ Gastroenterol. 2007;13(24):3392-3395. doi:10.3748/wjg.v13. i24.3392

4. Goukassian ID, Kussman SR, Toribio Y, Rosen JE. Secondary recurrent multiple EGIST of the mesentary: A case report and review of the literature. Int J Surg Case Rep. 2012;3(9):463-466. doi:10.1016/j. ijscr.2012.03.030

5. Fagkrezos D, Touloumis Z, Giannila M, Penlidis C, Papaparaskeva K, Triantopoulou C. Extra-gastrointestinal stromal tumor of the omentum: a rare case report and review of the literature. Rare Tumors. 2012;4(3):e44. doi:10.4081/rt.2012.e44

6. Barros A, Linhares E, Valadao M, et al. Extragastrointestinal stromal tumors (EGIST): a series of case reports. Hepato-Gastroenterology. 2011;58(107-108):865-868.

7. Agaimy A, Wunsch PH. Gastrointestinal stromal tumours: a regular origin in the muscularis propria, but an extremely diverse gross presentation. A review of 200 cases to critically re-evaluate the concept of so-called extra-gastrointestinal stromal tumours. Langenbeck's Archives Surgery. 2006;391(4):322-329. doi:10.1007/ s00423-005-0005-5

8. Hanayneh W, Starr J, George TJ Jr, Parekh H. Extragastrointestinal stromal tumors of the pelvic cavity and the vagina: two case reports and review of the literature. Gynecol Oncol Rep. 2018;25:3-7. doi:10.1016/j.gore.2018.04.006

9. Ceballos KM, Francis JA, Mazurka JL. Gastrointestinal stromal tumor presenting as a recurrent vaginal mass. Arch Pathol Lab Med. 2004;128(12):1442-1444.

10. Munoz M, Echeverri C, Ramirez PT, Echeverri L, Pareja LR. Extragastrointestinal stromal tumor in the rectovaginal septum in an adolescent. Gynecol Oncol Case Reports. 2013;5:67-69. doi:10.1016/ j.gynor.2013.05.004

11. Lam MM, Corless CL, Goldblum JR, Heinrich MC, Downs-Kelly E, Rubin BP. Extragastrointestinal stromal tumors presenting as vulvovaginal/rectovaginal septal masses: a diagnostic pitfall. Int $J$ Gynecol Pathol. 2006;25(3):288-292. doi:10.1097/01. pgp.0000215291.22867.18

12. Nasu K, Ueda T, Kai S, et al. Gastrointestinal stromal tumor arising in the rectovaginal septum. Int $J$ Gynecol Cancer. 2004;14 (2):373-377. doi:10.1136/ijgc-00009577-200403000-00028

13. Weppler EH, Gaertner EM. Malignant extragastrointestinal stromal tumor presenting as a vaginal mass: report of an unusual case with literature review. Int J Gynecol Cancer. 2005;15(6):1169-1172. doi:10.1111/j.1525-1438.2005.00269.x

14. Takano M, Saito K, Kita T, Furuya K, Aida S, Kikuchi Y. Preoperative needle biopsy and immunohistochemical analysis for gastrointestinal stromal tumor of the rectum mimicking vaginal leiomyoma. Int $J$ Gynecol Cancer. 2006;16(2):927-930. doi:10.1111/j.1525-1438.2006.00217.x

15. Nagase S, Mikami Y, Moriya T, et al. Vaginal tumors with histologic and immunocytochemical feature of gastrointestinal stromal tumor: two cases and review of the literature. Int $j$ Gynecol Cancer. 2007;17 (4):928-933. doi:10.1111/j.1525-1438.2007.00892.x

16. Zhang W, Peng Z, Xu L. Extragastrointestinal stromal tumor arising in the rectovaginal septum: report of an unusual case with literature review. Gynecol Oncol. 2009;113(3):399-401. doi:10.1016/j.ygyno. 2009.02.019
17. Vazquez J, Perez-Pena M, Gonzalez B, Sanchez A. Gastrointestinal stromal tumor arising in the rectovaginal septum. J Low Genit Tract Dis. 2012;16(2):158-161. doi:10.1097/LGT.0b013e31823b52af

18. Liu QY, Kan YZ, Zhang MY, Sun TY, Kong LF. Primary extragastrointestinal stromal tumor arising in the vaginal wall: significant clinicopathological characteristics of a rare aggressive soft tissue neoplasm. World J Clin Cases. 2016;4(4):118-123. doi:10.12998/ wjcc.v4.i4.118

19. Yamamoto H, Kojima A, Nagata S, Tomita Y, Takahashi S, Oda Y. KIT-negative gastrointestinal stromal tumor of the abdominal soft tissue: a clinicopathologic and genetic study of 10 cases. Am J Surg Pathol. 2011;35(9):1287-1295. doi:10.1097/PAS.0b013e3182206f15

20. Kim KH, Nelson SD, Kim DH, et al. Diagnostic relevance of overexpressions of PKC-theta and DOG-1 and KIT/PDGFRA gene mutations in extragastrointestinal stromal tumors: a Korean six-centers study of 28 cases. Anticancer Res. 2012;32(3):923-937.

21. Yamamoto H, Oda Y, Kawaguchi K, et al. c-kit and PDGFRA mutations in extragastrointestinal stromal tumor (gastrointestinal stromal tumor of the soft tissue). Am J Surg Pathol. 2004;28(4):479-488. doi:10.1097/00000478-200404000-00007

22. Faussone-Pellegrini MS, Thuneberg L. Guide to the identification of interstitial cells of Cajal. Microsc Res Tech. 1999;47(4):248-266. doi:10.1002/(SICI)1097-0029(19991115)47:4<248::AID-JEMT4>3. $0 . \mathrm{CO} ; 2-\mathrm{W}$

23. Badalamenti G, Rodolico V, Fulfaro F, et al. Gastrointestinal stromal tumors (GISTs): focus on histopathological diagnosis and biomolecular features. Ann Oncol. 2007;18(Suppl 6):vi136-140. doi:10.1093/ annonc/mdm 243

24. Cecka F, Jon B, Ferko A, Subrt Z, Nikolov DH, Tycova V. Long-term survival of a patient after resection of a gastrointestinal stromal tumor arising from the pancreas. Hepatobiliary Pancreatic Diseases Int. 2011;10(3):330-332. doi:10.1016/S1499-3872(11)60056-8

25. Nishida T, Blay JY, Hirota S, Kitagawa Y, Kang YK. The standard diagnosis, treatment, and follow-up of gastrointestinal stromal tumors based on guidelines. Gastric Cancer. 2016;19(1):3-14. doi:10.1007/ s10120-015-0526-8

26. Guo T, Hajdu M, Agaram NP, et al. Mechanisms of sunitinib resistance in gastrointestinal stromal tumors harboring KITAY502-3ins mutation: an in vitro mutagenesis screen for drug resistance. Clin Cancer Res. 2009;15(22):6862-6870. doi:10.1158/1078-0432.CCR-09-1315

27. Demetri GD, Reichardt P, Kang YK, et al. Efficacy and safety of regorafenib for advanced gastrointestinal stromal tumours after failure of imatinib and sunitinib (GRID): an international, multicentre, randomised, placebo-controlled, Phase 3 trial. Lancet. 2013;381 (9863):295-302. doi:10.1016/S0140-6736(12)61857-1

28. Metaxas Y, Oikonomopoulos G, Pentheroudakis G. Update on clinical research and state of the art management of patients with advanced sarcomas and GIST. ESMO Open. 2016;1(3):e000065. doi:10.1136/esmoopen-2016-000065

29. George S, Wang Q, Heinrich MC, et al. Efficacy and safety of regorafenib in patients with metastatic and/or unresectable GI stromal tumor after failure of imatinib and sunitinib: a multicenter Phase II trial. $J$ clin oncol. 2012;30(19):2401-2407. doi:10.1200/JCO.2011.39.9394

30. Evans EK, Gardino AK, Kim JL, et al. A precision therapy against cancers driven by KIT/PDGFRA mutations. Sci Transl Med. 2017;9:414. doi:10.1126/scitranslmed.aao1690

31. American Association for Cancer Research. Avapritinib approved for GIST subgroup. Cancer Discovery. 2020;10(3):334. doi:10.1158/ 2159-8290.CD-NB2020-003

32. Dhillon S. Avapritinib: first approval. Drugs. 2020;80(4):433-439. doi:10.1007/s40265-020-01275-2

33. United States Securities And Exchange Commission. Form 8-K. http://ir.blueprintmedicines.com/static-fles/760ac82a-c1ad4d52-bcbab3bd3bdb6310. 2020;Accessed Feb 10, 2020. 


\section{Publish your work in this journal}

OncoTargets and Therapy is an international, peer-reviewed, open access journal focusing on the pathological basis of all cancers, potential targets for therapy and treatment protocols employed to improve the management of cancer patients. The journal also focuses on the impact of management programs and new therapeutic

Submit your manuscript here: https://www.dovepress.com/oncotargets-and-therapy-journa agents and protocols on patient perspectives such as quality of life, adherence and satisfaction. The manuscript management system is completely online and includes a very quick and fair peer-review system, which is all easy to use. Visit http://www.dovepress.com/ testimonials.php to read real quotes from published authors. 